'Department of Nephrology, Sisli Hamidiye Etfal Educational and Research Hospital, Istanbul, Turkey.

2Department of Cardiology, Haseki Educational and Research Hospital, Istanbul, Turkey.

${ }^{3}$ Department of Cardiology, Dr. Siyami Ersek Thoracic and Cardiac Surgery Educational and Research Hospital, Turkey.

Recibido el 4 de marzo de 2015, aceptado el 16 de octubre de 2015.

Address all correspondence to: Tuncay Sahutoglu, MD Fellow in nephrology

Sisli Hamidiye Etfal Educational and Research Hospital

Halaskargazi Cad. EtfalSok. 34371, Sisli, Istanbul, Turkey. tu_cay83@yahoo.com

\section{Familial Mediterranean Fever is associated with abnormal ventricular repolarization indices}

\author{
ELBIS AHBAP ${ }^{1}$, TAMER SAKACI ${ }^{1}$, EKREM KARA ${ }^{1}$, \\ TUNCAY SAHUTOGLU' ${ }^{\prime}$, SEMI OZTURK ${ }^{2}$, \\ TANER BASTURK ${ }^{1}$, YENER KOC ${ }^{1}$, MUSTAFA SEVINC ${ }^{1}$, \\ CUNEYT AKGOL ${ }^{1}, Z^{2}$ UHAL ATAN UCAR ${ }^{1}$, \\ ARZU OZDEMIR KAYALAR ${ }^{1}$, FEYZA BAYRAKTAR CAGLAYAN ${ }^{1}$, \\ SEYFETTIN GURBUZ ${ }^{3}$, ABDULKADIR UNSAL ${ }^{1}$
}

\title{
ABSTRACT
}

Background: Cardiac arrhythmias can be a part of cardiovascular involvement in some rheumatic diseases, but data about familial Mediterranean fever (FMF) are conflicting. Aim: To search for abnormalities in ventricular repolarization indices in FMF patients. Patients and Methods: Seventy seven FMF patients and 30 age/gender comparable healthy controls were included. All patients were attack free and subjects with disease or drugs that are known to alter cardiac electrophysiology were excluded. Electrocardiographic data were obtained and analyzed. Results: Twelve FMF patients had amyloidosis. QT and QTc intervals were within the normal ranges and similar between FMF patients and healthy controls. QT dispersion, peak to end interval of T wave (Tpe), Tpe/ $Q T$ and Tpe/QTc ratios were significantly higher in FMF patients than in healthy controls. Patients with amyloidosis had significantly higher QT dispersion, Tpe, Tpe/QT and Tpe/QTc than their counterparts without FMF. Levels of proteinuria were moderately correlated with QT dispersion, Tpe, Tpe/QT and Tpe/ QTc. Conclusions: FMF patients may have an increased risk for arrhythmias.

(Rev Med Chile 2015; 143: 1560-1568)

Key words: Arrhythmias, cardiac; Familial Mediterranean fever; Rheumatic diseases.

\section{La fiebre mediterránea familiar se asocia a anomalías en la repolarización ventricular}

Antecedentes: Las arritmias cardiacas pueden ser parte del compromiso cardíaco en enfermedades reumáticas, sin embargo, no se sabe con certeza si esto ocurre en la fiebre mediterránea familiar (FMF). Objetivo: Buscar anomalías en la repolarización ventricular en pacientes con FMF. Pacientes y Métodos: Sesenta y siete pacientes como FMF y 30 controles sanos pareados por edad y género fueron estudiados. Todos los pacientes estaban en período intercrítico y no usaban medicamentos o tenían enfermedades concomitantes que pudieran causar anomalías electrocardiográficas. Se analizaron los electrocardiogramas de estos participantes. Resultados: Veinte pacientes con FMF tenían amiloidosis. Los intervalos QT $y$ QTc eran normales y similares entre pacientes y controles. La dispersión del intervalo QT, el intervalo desde el peak al final de la onda $T$ (Tpe), 
las razones Tpe/QTy Tpe/QTc fueron significativamente más altos en los pacientes que en los controles. Los pacientes con amiloidosis tenían una dispersión de $Q T$, Tpe, Tpe/QT y Tpe/QTc mayores que sus pares sin la condición. Los niveles de proteinuria se correlacionaron moderadamente con los parámetros antes mencionados. Conclusiones: Los pacientes con FMF tienen mayor riesgo de arritmias.

F amilial Mediterranean Fever (FMF) is the most common form of periodic fever syndromes, which is caused by mutations in the MEFV gene. It is characterized by sporadic unpredictable attacks of fever, arthritis and serositis ${ }^{1}$. The prevalence is particularly higher in certain ethnic groups within the Mediterranean basin, such as Sephardic Jews, Armenians, Turks, Arabs and Druze ${ }^{2}$. The diagnosis is usually made on clinical basis and the genetic tests for MEFV gene are supportive.

Aside from symptoms and signs of episodic attacks of inflammation, FMF is a major cause of accumulation of amyloid A amyloidosis (AAA). AAA secondary to FMF can involve many different organs, but most frequently the kidneys, spleen, liver and gut. One of the earliest targets of AAA in FMF is the kidney, which can be manifested initially with isolated proteinuria and later with increased creatinine levels.

Cardiovascular system is an important target of AAA, with significant morbidity and mortality at advanced stages. FMF may cause pericarditis due to serositis and/or cardiac amyloidosis as a part of the systemic disease ${ }^{3}$. Recent studies investigated repolarization abnormalities using markers such as QT dispersion, transmural dispersion of repolarization and $\mathrm{P}$-wave dispersion in FMF patients with and without $\mathrm{AAA}^{4-6}$. Peak to end interval of $T$ wave is newermarker of cardiac repolarization abnormality, which has been suggested as a better predictor of sudden cardiac death or ventricular tachycardia ${ }^{7}$. We aimed to evaluate cardiac repolarization indices and their correlates in patients with FMF with and without AAA.

\section{Materials and Methods}

\section{Study population}

Patients who had been followed up between June 2004 and June 2014 in the outpatient clinic of Nephrology of Sisli Hamidiye Etfal Educational and Research Hospital and who were diagnosed with FMF according to Tel Hashomer criteria were included. Diagnosis of amyloidosis was confirmed by renal biopsy in all amyloidosis positive FMF patients. Past medical history and the medications of the patients were recorded. Exclusion criteria were history of congenital or acquired heart diseases, inflammatory attack within the previous month, drug ingestion that may have an effect on ECG, chronic diseases (such diabetes, hypertension, hypothyroidism, organ failure, etc.). Age and gender comparable healthy subjects were recruited as the control group.

This is a cross-sectional study in design and variables were obtained between September 2014 and December 2014. The following clinical and laboratory variables were recorded and used for analysis: age, gender, body-mass index(BMI), serum glucose, urea, creatinine levels, electrolytes $(\mathrm{Na}, \mathrm{K})$, albumin, lipids, fibrinogen, C-reactive protein (CRP), erythrocyte sedimentation rate (ESR), urine analysis, daily proteinuria, blood pressure, electrocardiography (ECG) and echocardiography $(\mathrm{ECHO})$ parameters.

BMI was calculated by dividing weight (kilograms) by height squared (meters). Plasma level of CRP was measured by nephelometric method and ESR was determined by the Westergreen method.

\section{Procedure}

All ECG recordings were obtained using the same 12-lead commercial device (Nihon Kohden, Cardiofax M, Tokyo, Japan) while the patients were resting in supine position for 10 minutes at a room temperature of $20-23^{\circ} \mathrm{C}$ between $09: 00$ and 14:00. The device was set at a $50 \mathrm{~mm} / \mathrm{s}$ paper speed and $2 \mathrm{mV} / \mathrm{cm}$. All participants were asked to avoid smoking, intake of caffeinated, alcoholic beverages and other stimulants within 3 hours and strenuous exercise 24 hours prior to study.

QT intervals were corrected according to the Bazett's formula (QTc) and the difference between maximum and minimum QTc intervals in each electrocardiogram was calculated as QT dispersion (QTd). 
The Tpe interval was measured as the distance between the peak and the end of $\mathrm{T}$ wave in the precordial lead V5 (or in leads V4 and V6 if not measurable in V5), and was corrected according to heart rate (Figures $1 \mathrm{a}$ and $1 \mathrm{~b}$ show samples of QT and Tpe measurements). Tpe/QTc ratio was calculated from these measurements. Subjects with $U$ waves on their ECGs were excluded from the study. All ECG measurements were performed by a single blinded observer.

\section{Statistical analysis}

SPSS 20.0 software (SPSS Inc, Chicago, USA) was used for statistical analysis. Parametric data were presented as mean \pm SD. Normality test was performed to all variables. Student t-test was used for parametric variables and Mann Whitney $U$ test was used for non-parametric distribution of variables. Spearman and Pearson tests were used for correlation analysis. Yates correction, chi-square test and Fisher's exact test were used for comparison of categorical data. One-way ANOVA with Tukey post-hoc analysis correction was used for intergroup analysis. Multivariate analyses were performed by logistic regression. $\mathrm{P}$ value $<0.05$ was considered as significant.

The study was approved by local Ethics Committee, and informed consent was obtained from each participant.

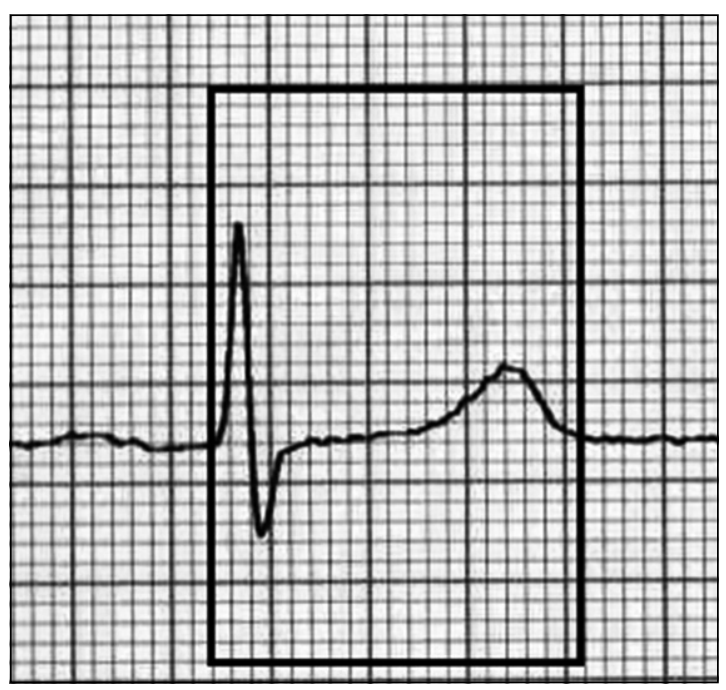

Figure 1a. Measurement of QT interval in an FMF patient without amyloidosis.

\section{Results}

\section{General characteristics}

Clinical characteristics, laboratory and echocardiographic parameters and repolarization indices of the FMF patients and the controls are shown in Table 1. There were 67 FMF patients and 30 healthy controls eligible to study. The mean disease duration was $9.1 \pm 8.2$ years and all FMF patients were receiving 1 to $1.5 \mathrm{mg} /$ day colchicine, orally.

All of the general characteristics were similar between FMF patients and the controls, except for mildly lower diastolic blood pressure and higher proteinuria, LV ejection fraction and LV mass index in the FMF group. Notably, inflammatory markers (ferritin, CRP, ESR and fibrinogen) were also similar between the two groups (Tables 1 and 2). However, patients with amyloidosis had higher levels of proteinuria, LV mass index, ESR and fibrinogen when compared to patients without amyloidosis (Table 3).

\section{Cardiac repolarization}

QT and QTc intervals were within the normal ranges and similar between the patients and controls ( $p>0.05)$, whereas Tpe interval, Tpe/ QT ratio and Tpe/QTc ratio were significantly increased in patients with FMF as compared to the healthy controls $(\mathrm{p}<0.001)$ (Table 2$)$.

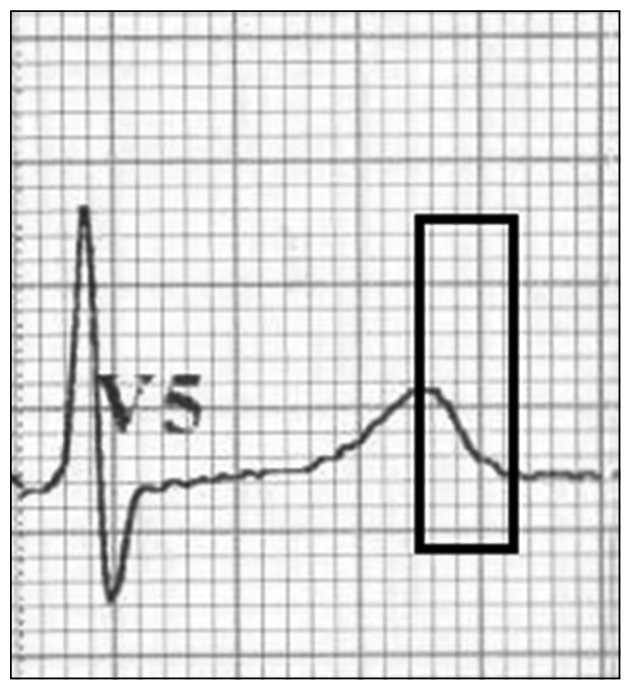

Figure 1b. Measurement of T peak to T end interval in a an FMF patient without amyloidois. 
Table 1. Comparison of demographic and laboratory parameters between healthy controls and FMF patients

\begin{tabular}{|c|c|c|c|}
\hline & Control $(n=30)$ & FMF $(n=67)$ & $\mathbf{p}$ \\
\hline $\begin{array}{l}\text { Demographics } \\
\text { Age (years) } \\
\text { Sex (male/female) }\end{array}$ & $\begin{array}{c}37.9 \pm 15.2 \\
13 / 17\end{array}$ & $\begin{array}{c}36.1 \pm 11.8 \\
30 / 37\end{array}$ & $\begin{array}{l}\text { NS } \\
\text { NS }\end{array}$ \\
\hline $\begin{array}{l}\text { FMF disease duration (years) } \\
\text { Weight }(\mathrm{kg}) \\
\text { Body mass index }\left(\mathrm{kg} / \mathrm{m}^{2}\right) \\
\text { Systolic BP }(\mathrm{mmHg}) \\
\text { Diastolic BP }(\mathrm{mmHg})\end{array}$ & $\begin{aligned} 71.9 & \pm 15.6 \\
25.3 & \pm 4.7 \\
115.5 & \pm 6.9 \\
74.5 & \pm 5.6\end{aligned}$ & $\begin{aligned} 9.1 & \pm 8.2 \\
69.9 & \pm 16.1 \\
25.6 & \pm 5.3 \\
113.7 & \pm 13.0 \\
71.0 & \pm 7.4\end{aligned}$ & $\begin{array}{l}\text { NS } \\
\text { NS } \\
\text { NS } \\
\text { NS } \\
\mathbf{0 . 0 0 9}\end{array}$ \\
\hline $\begin{array}{l}\text { Laboratory } \\
\text { Urea }(\mathrm{mg} / \mathrm{dL}) \\
\text { Creatinine }(\mathrm{mg} / \mathrm{dL}) \\
\text { Uric acid }(\mathrm{mmo} / \mathrm{L}) \\
\text { Sodium }(\mathrm{mmol} / \mathrm{L}) \\
\text { Potassium }(\mathrm{meq} / \mathrm{L}) \\
\text { Hemoglobin }(\mathrm{g} / \mathrm{dL}) \\
\text { Total cholesterol }(\mathrm{mmol} / \mathrm{L}) \\
\text { Triglyceride }(\mathrm{mmol} / \mathrm{L}) \\
\text { LDL }(\mathrm{mmol} / \mathrm{L}) \\
\mathrm{HDL}(\mathrm{mg} / \mathrm{dL}) \\
\text { Albumin }(\mathrm{g} / \mathrm{dl}) \\
\text { Ferritin }(\mathrm{ng} / \mathrm{mL}) \\
\text { Proteinuria }(\mathrm{mg} / 24 \mathrm{~h}) \\
\text { CRP }(\mathrm{mg} / \mathrm{L}) \\
\text { ESR }(\mathrm{mm} / \mathrm{h}) \\
\text { Fibrinogen }(\mathrm{mg} / \mathrm{dL})\end{array}$ & $\begin{aligned} 27.0 & \pm 9.0 \\
0.8 & \pm 0.1 \\
4.8 & \pm 1.1 \\
140.9 & \pm 2.4 \\
4.5 & \pm 0.4 \\
13.7 & \pm 1.7 \\
193.3 & \pm 29.3 \\
140.1 & \pm 103.6 \\
114.3 & \pm 22.1 \\
52.4 & \pm 15.9 \\
4.7 & \pm 0.3 \\
68.1 & \pm 51.4 \\
69.3 & \pm 34.6 \\
4.5 & \pm 2.2 \\
12.3 & \pm 6.4 \\
269.8 & \pm 57.6\end{aligned}$ & $\begin{aligned} 30.7 & \pm 17.1 \\
0.9 & \pm 0.4 \\
4.7 & \pm 1.5 \\
139.8 & \pm 2.1 \\
4.4 & \pm 0.4 \\
13.3 & \pm 1.6 \\
179.9 & \pm 40.7 \\
119.0 & \pm 80.8 \\
106.5 & \pm 37.4 \\
49.5 & \pm 12.7 \\
4.5 & \pm 0.5 \\
61.0 & \pm 72.5 \\
605.8 & \pm 1834.8 \\
7.1 & \pm 11.5 \\
15.5 & \pm 16.0 \\
281.6 & \pm 75.2\end{aligned}$ & $\begin{array}{l}\text { NS } \\
\text { NS } \\
\text { NS } \\
\text { NS } \\
\text { NS } \\
\text { NS } \\
\text { NS } \\
\text { NS } \\
\text { NS } \\
\text { NS } \\
\text { NS } \\
\text { NS } \\
<0.001 \\
\text { NS } \\
\text { NS } \\
\text { NS }\end{array}$ \\
\hline
\end{tabular}

Mann-Whitney U test. BP, blood pressure; LDL, low density cholesterol; HDL, high density cholesterol; CRP, C-reactive protein; ESR, erythrocyte sedimentation rate.

Table 2. Comparison of echocardiographic and ventricular repolarization parameters between healthy controls and FMF patients

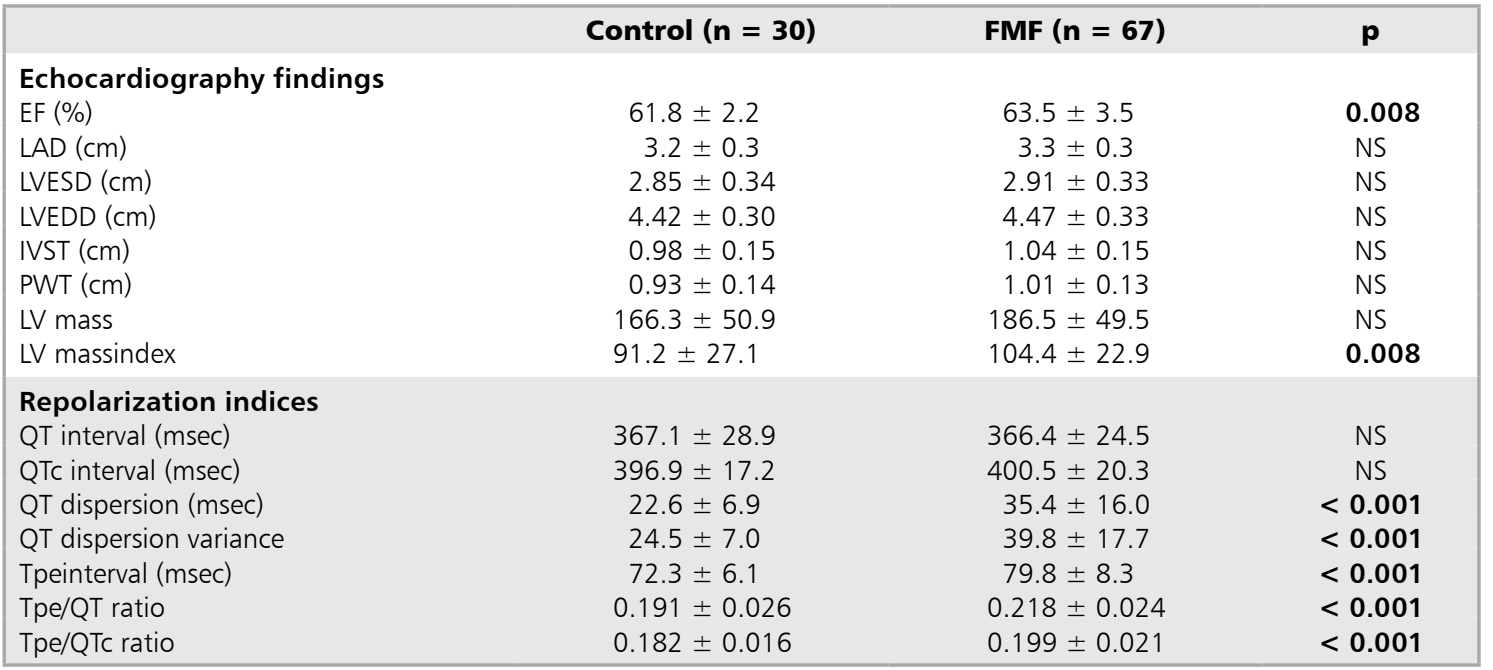

Mann-Whitney U test. EF, ejection fraction; LAD, left atrium diameter; LVESD, left ventricular end systolic diameter; LVEDD, left ventricular end diastolic diameter; IVST, interventricular septum thickness; PWT, posterior wall thickness. 

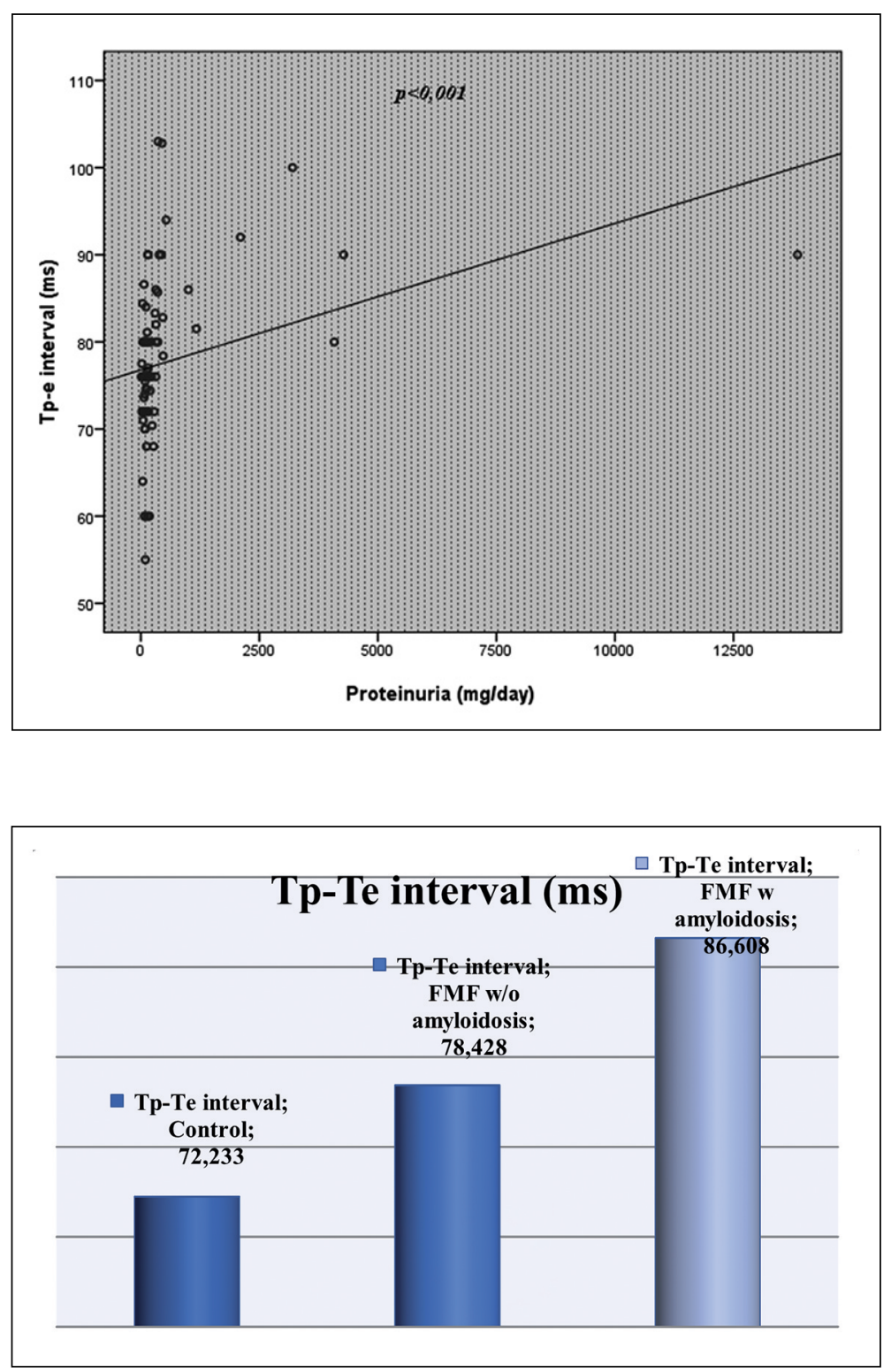

Figure 2. Spearman correlation between levels of proteinuria and Tpe intervals.
Figure 3. Comparison of mean Tpe intervals between the control group, amyloidosis negative and positive FMF patients.
When repolarization indices were compared between FMF patients with and without amyloidosis, we found that QT and QTc intervals were within the normal ranges and similar between the two groups, whereas Tpe interval, Tpe/QT and Tpe/QTc ratios were higher in patients who had amyloidosis as compared to those without amyloidosis (Table 4 and Figure 3). Tpe interval, Tpe/QT and Tpe/QTc ratios still remained higher in FMF patients as compared to healthy controls, even after the patients with amyloidosis were excluded from the analysis.

\section{Correlation analysis}

Proteinuria and the presence of amyloidosis showed moderate correlations with Tpe interval, Tpe/QT and Tpe/QTc ratios, but not with QT or QTc intervals (Table 5). Tpe interval was weakly correlated with male gender, serum albumin, left atrial diameter, LVEDD and moderately with 
Table 3. Comparison of demographic and laboratory parameters between FMF patients with and without amyloidosis

\begin{tabular}{|c|c|c|c|}
\hline & Amyloidosis $(-)(n=55)$ & Amyloidosis $(+)(n=12)$ & $\mathbf{p}$ \\
\hline $\begin{array}{l}\text { Demographics } \\
\text { Age (years) } \\
\text { Sex (male/female) }\end{array}$ & $\begin{array}{c}36.0 \pm 12.4 \\
23 / 32\end{array}$ & $\begin{array}{c}36.9 \pm 8.7 \\
7 / 5\end{array}$ & $\begin{array}{l}\text { NS } \\
\text { NS }\end{array}$ \\
\hline $\begin{array}{l}\text { Duration of amyloidosis (years) } \\
\text { Weight }(\mathrm{kg}) \\
\text { Body mass index }\left(\mathrm{kg} / \mathrm{m}^{2}\right) \\
\text { Systolic BP }(\mathrm{mmHg}) \\
\text { Diastolic BP }(\mathrm{mmHg})\end{array}$ & $\begin{aligned} 71.1 & \pm 15.7 \\
26.0 & \pm 5.5 \\
114.1 & \pm 12.8 \\
71.2 & \pm 6.9\end{aligned}$ & $\begin{aligned} 5.1 & \pm 4.0 \\
64.4 & \pm 17.2 \\
23.5 & \pm 4.1 \\
111.6 & \pm 14.0 \\
70.0 & \pm 9.5\end{aligned}$ & $\begin{array}{l}\text { NS } \\
\text { NS } \\
\text { NS } \\
\text { NS }\end{array}$ \\
\hline $\begin{array}{l}\text { Laboratory } \\
\text { Urea }(\mathrm{mg} / \mathrm{dL}) \\
\text { Creatinine }(\mathrm{mg} / \mathrm{dL}) \\
\text { Uric acid }(\mathrm{mmol} / \mathrm{L}) \\
\text { Sodium }(\mathrm{mmol} / \mathrm{L}) \\
\text { Potassium }(\mathrm{meg} / \mathrm{L}) \\
\text { Hemoglobin }(\mathrm{g} / \mathrm{dL}) \\
\text { Total cholesterol }(\mathrm{mmol} / \mathrm{L}) \\
\text { Triglyceride }(\mathrm{mmol} / \mathrm{L}) \\
\text { LDL }(\mathrm{mmol} / \mathrm{L}) \\
\mathrm{HDL}(\mathrm{mg} / \mathrm{dL}) \\
\text { Albumin }(\mathrm{g} / \mathrm{dl}) \\
\text { Ferritin }(\mathrm{ng} / \mathrm{mL}) \\
\text { Proteinuria }(\mathrm{mg} / 24 \mathrm{~h}) \\
\text { CRP }(\mathrm{mg} / \mathrm{L}) \\
\text { ESR }(\mathrm{mm} / \mathrm{h}) \\
\text { Fibrinogen }(\mathrm{mg} / \mathrm{dL})\end{array}$ & $\begin{aligned} 28.1 & \pm 13.4 \\
0.85 & \pm 0.32 \\
4.5 & \pm 1.3 \\
139.7 & \pm 2.0 \\
4.3 & \pm 0.3 \\
13.3 & \pm 1.7 \\
176.2 & \pm 34.6 \\
116.4 & \pm 83.9 \\
103.8 & \pm 30.1 \\
49.6 & \pm 11.4 \\
4.6 & \pm 0.3 \\
54.2 & \pm 56.3 \\
166.5 & \pm 121.6 \\
7.2 & \pm 12.6 \\
11.8 & \pm 8.0 \\
264.6 & \pm 57.7\end{aligned}$ & $\begin{aligned} 42.6 & \pm 26.0 \\
1.19 & \pm 0.74 \\
5.7 & \pm 1.9 \\
140.3 & \pm 2.4 \\
4.6 & \pm 0.5 \\
13.3 & \pm 1.3 \\
197.1 & \pm 60.4 \\
130.5 & \pm 66.0 \\
118.6 & \pm 61.2 \\
48.7 & \pm 18.3 \\
4.0 & \pm 0.9 \\
92.2 & \pm 121.1 \\
2619 & \pm 3839 \\
7.0 & \pm 5.1 \\
32.0 & \pm 29.2 \\
359.3 & \pm 97.8\end{aligned}$ & $\begin{array}{l}\mathbf{0 . 0 3 4} \\
\text { NS } \\
0.002 \\
\text { NS } \\
\text { NS } \\
\text { NS } \\
\text { NS } \\
\text { NS } \\
\text { NS } \\
\text { NS } \\
\mathbf{0 . 0 0 6} \\
\text { NS } \\
<0.001 \\
\text { NS } \\
\mathbf{0 . 0 0 3} \\
\mathbf{0 . 0 0 2}\end{array}$ \\
\hline
\end{tabular}

Mann-Whitney U test. BP, blood pressure; LDL, low density cholesterol; HDL, high density cholesterol; CRP, C-reactive protein; ESR, erythrocyte sedimentation rate.

Table 4. Comparison of echocardiographic and ventricular repolarization parameters between healthy controls and FMF patients with and without amyloidosis

\begin{tabular}{|c|c|c|c|c|}
\hline & $\begin{array}{l}\text { Control } \\
(n=30)\end{array}$ & $\begin{array}{l}\text { Amyloidosis (-) } \\
\quad(n=55)\end{array}$ & $\begin{array}{l}\text { Amyloidosis (+) } \\
\quad(n=12)\end{array}$ & $\mathbf{p}$ \\
\hline \multicolumn{5}{|c|}{ Echocardiography findings } \\
\hline $\mathrm{EF}(\%)$ & $61.8 \pm 2.2$ & $63.6 \pm 3.7$ & $63.0 \pm 2.2$ & 0.007 \\
\hline LAD $(\mathrm{cm})$ & $3.2 \pm 0.3$ & $3.3 \pm 0.3$ & $3.5 \pm 0.3$ & NS \\
\hline $\operatorname{LVESD}(\mathrm{cm})$ & $2.85 \pm 0.34$ & $2.88 \pm 0.30$ & $3.03 \pm 0.45$ & NS \\
\hline $\operatorname{LVEDD}(\mathrm{cm})$ & $4.42 \pm 0.30$ & $4.45 \pm 0.31$ & $4.60 \pm 0.40$ & NS \\
\hline IVST (cm) & $0.98 \pm 0.15$ & $1.05 \pm 0.15$ & $1.01 \pm 0.11$ & NS \\
\hline PWT (cm) & $0.93 \pm 0.14$ & $1.01 \pm 0.14$ & $1.00 \pm 00.9$ & NS \\
\hline LV mass & $166.3 \pm 50.9$ & $185.6 \pm 49.0$ & $190.6 \pm 53.8$ & NS \\
\hline LV mass index & $91.2 \pm 27.1$ & $102.9 \pm 22.5$ & $111.3 \pm 24.6$ & 0.014 \\
\hline \multicolumn{5}{|l|}{ Repolarization indices } \\
\hline QT interval (msec) & $367.1 \pm 28.9$ & $366.2 \pm 23.1$ & $366.9 \pm 31.3$ & NS \\
\hline QTc interval (msec) & $396.9 \pm 17.2$ & $400.6 \pm 19.8$ & $400.4 \pm 23.2$ & NS \\
\hline QT dispersion (msec) & $22.6 \pm 6.9$ & $32.6 \pm 14.7$ & $48.3 \pm 15.8$ & $<0.001$ \\
\hline QT dispersion variance & $24.5 \pm 7.0$ & $36.9 \pm 16.9$ & $52.9 \pm 15.9$ & $<0.001$ \\
\hline Tpe interval (msec) & $72.3 \pm 6.1$ & $78.4 \pm 8.1$ & $86.6 \pm 5.6$ & $<0.001$ \\
\hline Tpe/QT ratio & $0.191 \pm 0.026$ & $0.214 \pm 0.025$ & $0.234 \pm 0.015$ & $<0.001$ \\
\hline Tpe/QTc ratio & $0.182 \pm 0.016$ & $0.196 \pm 0.020$ & $0.216 \pm 0.015$ & $<0.001$ \\
\hline
\end{tabular}

Mann-Whitney $U$ test. EF, ejection fraction; LAD, left atrium diameter; LVESD, left ventricular end systolic diameter; LVEDD, left ventricular end diastolic diameter; IVST, interventricular septum thickness; PWT, posterior wall thickness. 
Table 5. Correlation analysis of ventricular repolarization indices with proteinuria and amyloidosis

\begin{tabular}{|lcccc|}
\hline & Proteinuria & \multicolumn{1}{c|}{ Amyloidosis } \\
Repolarization indices & $\mathbf{r}$ & $\mathbf{p}$ & $\mathbf{r}$ & NS \\
QT interval (msec) & -0.142 & NS & -0.037 & NS \\
QTc interval (msec) & -0.031 & $<\mathbf{0 . 0 0 1}$ & +0.008 & $<\mathbf{0 . 0 0 1}$ \\
QT dispersion (msec) & +0.538 & $<\mathbf{0 . 0 0 1}$ & +0.393 & $<\mathbf{0 . 0 0 1}$ \\
QT dispersion variance & +0.580 & $<\mathbf{0 . 0 0 1}$ & +0.463 & $<\mathbf{0 . 0 0 1}$ \\
Tpe interval (msec) & +0.500 & $<\mathbf{0 . 0 0 1}$ & +0.401 & $<\mathbf{0 0 1}$ \\
Tpe/QT ratio & +0.537 & $<\mathbf{0 . 0 0 1}$ & +0.393 & $<\mathbf{0 0 1}$ \\
Tpe/QTc ratio & +0.475 & & & \\
\hline
\end{tabular}

Spearman correlation analysis.

Table 6. Correlation analysis of Tpe with clinical and laboratory parameters

\begin{tabular}{|c|c|c|}
\hline Tpe & $\mathbf{r}$ & $\mathbf{p}$ \\
\hline Age & -0.060 & NS \\
\hline Male gender & +0.291 & 0.004 \\
\hline Presence of amyloidosis & +0.463 & $<0.001$ \\
\hline Systolic BP & +0.040 & NS \\
\hline Diastolic BP & -0.072 & NS \\
\hline Proteinuria & +0.500 & $<0.001$ \\
\hline Albumin & -0.269 & 0.008 \\
\hline LAD & +0.283 & 0.005 \\
\hline LV mass & +0.301 & 0.003 \\
\hline LV mass index & +0.399 & $<0.001$ \\
\hline PWT & +0.305 & 0.002 \\
\hline IVST & +0.193 & NS \\
\hline LVESD & +0.340 & 0.001 \\
\hline LVEDD & +0.207 & 0.041 \\
\hline CRP & +0.151 & NS \\
\hline ESR & +0.143 & NS \\
\hline Fibrinogen & +0.131 & NS \\
\hline Urea & +0.052 & NS \\
\hline Creatinine & +0.165 & NS \\
\hline $\mathrm{Na}$ & -0.005 & NS \\
\hline K & +0.026 & NS \\
\hline Total cholesterol & -0.128 & NS \\
\hline TG & -0.049 & NS \\
\hline $\mathrm{HDL}$ & -0.005 & NS \\
\hline LDL & -0.135 & NS \\
\hline
\end{tabular}

$\mathrm{BP}$, blood pressure; LDL, low density cholesterol; $\mathrm{HDL}$, high density cholesterol; CRP, C-reactive protein; ESR, erythrocyte sedimentation rate; $E F$, ejection fraction; $L A D$, left atrium diameter; LVESD, left ventricular end systolic diameter; LVEDD, left ventricular end diastolic diameter; IVST, interventricular septum thickness; PWT, posterior wall thickness. amyloidosis, proteinuria, LV mass index, posterior wall thickness, and LVESD (Table 6 and Figure 2). There were no correlations between Tpe and age, inflammatory markers, blood pressure and the other laboratory parameters (Table 6).

\section{Discussion}

Several rheumatic disorders, such as rheumatoid arthritis and systemic lupus erythematosus, have been shown be associated with cardiovascular morbidity and mortality, that cannot be attributed to traditional cardiovascular risk factors ${ }^{8}$. Major causes for these adverse cardiovascular effects are accelerated atherosclerosis, small vessel vasculitis within the heart, degeneration of the conduction system, and endocardium damage. Cardiac arrhythmias and conduction disturbances are part of the consequences of cardiac involvement in rheumatic diseases ${ }^{9}$. Likewise, secondary amyloidosis can produce cardiac arrhythmias and conduction disturbances as a result of deposition of amyloid fibrils within the myocardium and possibly autonomic nervous system dysfunctions ${ }^{10}$.

Nussinovitchetal published several studies regarding cardiac repolarization abnormalities in FMF patients. In their studies, FMF patients with and without amyloidosis had similar repolarization indices (QT interval, QTc interval and QT dispersion) to those of healthy controls ${ }^{5,11}$. When colchicine resistant FMF patients were compared to healthy controls, they also revealed that cardiac repolarization indices were similar between the two groups ${ }^{12}$. Another study from Turkey with a similar design also found that there were not differences in ventricular repolarization indices 
between FMF patients and healthy controls ${ }^{13}$. Giese et al compared FMF patients without amyloidosis and Nussinovitch et al. compared FMF patients with amyloidosis to health controls to searched for supraventricular indices. Both of them found that $\mathrm{P}$-wave duration and dispersions were comparable between FMF patients and healthy controls ${ }^{14,15}$.

Young FMF patients with relatively short disease duration were included in this study to investigate cardiac arrhythmogenicity basis before and early after the development of overt amyloidosis. The sample size was relatively larger than previous studies and all patients were under colchicine treatment. QT interval and QTc values of both FMF patients and healthy controls were within the normal rangesand comparable, like findings in the aforementioned studies. However, in contrast to some of the previous studies, all indices that reflect ventricular repolarization abnormalities were significantly higher in FMF patients than in healthy controls. When we separated patients with and without amyloidosis, we found that QTd was higher in amyloidosis negative FMF patients than in healthy controls. This value was even higher in amyloidosis positive than in amyloidosis negative FMF patients. LV mass indices and the levels of proteinuria were highest in amyloidosis positive FMF patients and lowest in healthy controls. Proteinuria and amyloidosis were factors showing the best correlation with QTd. Markers of inflammation were comparable between healthy controls and FMF patients and they were not correlated with QTd.

In a cross-sectional study by Akcay et al., QTd was found to be higher in FMF patients similar to our results ${ }^{4}$. Arslan et al. looked for atrial arrhythmogenicity in pediatric FMF patients, and unlike other studies theyfound that $\mathrm{P}$ wave dispersion was higher in FMF patients than in healthy controls ${ }^{16}$.

Tpe interval is a relatively newer marker of ventricular arrhythmia and suggested to correspond to transmural dispersion of repolarization. Tpe/QT is constant at normal heart rates and has a mean value of 0.21 in healthy individuals ${ }^{17}$. Tpe and Tpe/QT were found to be associated with adverse outcomes in patients with myocardial infarction, Brugada syndrome, bradyarrhythmia, and hypertrophic cardiomyopathy $y^{7,18-20}$. Tpe and Tpe/QT have not been studied previouslyto eva- luate ventricular repolarization in FMF patients. In our study, Tpe, Tpe/QT and Tpe/QTc were significantly higher in FMF patients as compared to healthy controls. These parameters were even more increased in patients who developed amyloidosis than in patients without amyloidosis. In correlation analysis, these parameters showed similar results to QTd correlations. Proteinuria, amyloidosis and LV mass index were factors showing the best correlation with Tpe, Tpe/QT and Tpe/QTc. These findings suggest that there may be subclinical amyloid deposition within the myocardium before the development of detectable cardiac amyloidosis, and the presence of renal amyloidosis (or proteinuria) may be a sign of more advanced disease.

Our studyindicates that there may be subclinical arrhythmogenic potential in FMF patients, even before the development of overt amyloidosis. However, there is a lot of controversy in the literature regarding to whether there are repolarization abnormalities or tendency to arrhythmia in patients with FMF. The causes of this may include limitations of study designs, inter-observer and intra-observer variability in measuring intervals from ECG recordings, and using different ECG recorders. Another aspect of such studies is that they do not show whether the actual risk of ventricular arrhythmia is increased in FMF. In a prospective design, 24 to 72 hours of continuous ECG recordings in a large cohort of FMF patients and computer based measurements may provide with the actual prevalence of arrhythmia and its correlation to repolarization indices.

\section{Conclusions}

QTd, Tpe, Tpe/QT and Tpe/QTc were higher in FMF patients as compared to healthy controls, and these parameters were even more elevated in patients who developed amyloidosis. These parameters were moderately correlated with proteinuria, amyloidosis and LV mass index. Increased Tpe in FMF was shown in this study for the first time to our knowledge. The clinical significance of these findings has not been shown yet, but they suggest that arrhythmogenic potential may be increased in FMF patients. Data in the literature are not uniform and better study designs are needed to answer unresolved questions. 


\section{References}

1. Onen F. Familial Mediterranean fever. Rheumatol Int 2006; 26: 489-96.

2. Sohar E, Gafni J, Pras M, Heller H. Familial Mediterranean fever. Asurvey of 470 cases and review of the literature. Am J Med 1967; 43: 227-53.

3. Dabestani A, Noble LM, Child JS, Krivokapich J, Schwabe AD. Pericardial disease in familial Mediterranean fever: An echocardiographic study. Chest 1982; 81 (5): 592-5.

4. Akcay A, Acar G, Sayarlioglu M, Sokmen A, Kaya H, Ispiroglu $\mathrm{M}$, et al. QT dispersion and transmural dispersion of repolarization in patients with familial Mediterranean fever. Mod Rheumatol 2009; 19 (5): 550-5.

5. Nussinovitch U, Nussinovitch $\mathrm{N}$, Nussinovitch $\mathrm{M}$, Volovitz B, Feld O, Ben-Zvi I, et al. QT dispersion in amyloidosis due to familial Mediterranean fever. Rheumatol Int 2012; 32 (7): 1945-8.

6. Nussinovitch N, Livneh A, Katz K, Langevitz P, Feld O, Nussinovitch $\mathrm{M}$, et al. QT dispersion in uncomplicated familial Mediterranean fever. Clin Rheumatol 2010; 29 (12): 1353-6.

7. Shimizu M, Ino H, Okeie K, Yamaguchi M, Nagata $\mathrm{M}$, Hayashi $\mathrm{K}$, et al. T-peak to T-end interval may be a better predictor of high-risk patients with hypertrophic cardiomyopathy associated with a cardiac troponin I mutation than QT dispersion. Clin Cardiol 2002; 25 (7): 335-9.

8. Shoenfeld Y, Gerli R, Doria A, Matsuura E, Cerinic MM, Ronda N, et al. Accelerated atherosclerosis in autoimmune rheumatic diseases. Circulation 2005; 112 (21): 3337-47.

9. Seferović PM, Ristić AD, Maksimović R, Simeunović DS, Ristić GG, Radovanović G, et al. Cardiac arrhythmias and conduction disturbances in autoimmune rheumatic diseases. Rheumatology (Oxford) 2006; 45 Suppl 4: iv39-42.

10. Desai HV, Aronow WS, Peterson SJ, Frishman WH. Cardiac amyloidosis: Approaches to diagnosis and management. Cardiol Rev 2010; 18 (1): 1-11.

11. Nussinovitch U, Kaminer K, Nussinovitch M, Volovitz
B, Lidar M, Nussinovitch N, et al. QT interval variability in familial Mediterranean fever: a study in colchicine-responsive and colchicine-resistant patients. Clin Rheumatol 2012; 31 (5): 795-9.

12. Nussinovitch U, Livneh A, Volovitz B, Nussinovitch M, Ben-Zvi I, Lidar M, et al. Normal QT dispersion in colchicine-resistant familial Mediterranean fever (FMF). Clin Rheumatol 2012; 31 (7): 1093-6.

13. Topal F, Tanindi A, Kurtoglu H, Akbulut S, Kucukazman M. QT Dispersion is Not Increased in Familial Mediterranean Fever. J Int Med Res 2011; 39 (5): 2006-11.

14. Giese A, Ornek A, Kurucay M, Kara K, Wittkowski H, Gohar F, et al. $\mathrm{P}$ wave dispersion and QT dispersion in adult Turkish migrants with familial Mediterranean fever living in Germany. Int J Med Sci. 2014; 11 (11): 1140-6.

15. Nussinovitch U, Livneh A, Nussinovitch M, Volovitz B, Ben-Zvi I, Lidar M, et al. P-wave dispersion in systemic AA amyloidosis of familial Mediterranean fever. Clin Rheumatol 2011; 30 (10): 1295-8.

16. Arslan D, Oran B, Yazılitas F, Peru H, Cimen D, Vatansev H. P-wave duration and dispersion in children with uncomplicated familial Mediterranean fever. Mod Rheumatol 2013; 23 (6): 1166-71.

17. Gupta P, Patel C, Patel H, Narayanaswamy S, Malhotra $\mathrm{B}$, Green JT, et al. T (p-e)/QT ratio as an index of arrhythmogenesis. J Electrocardiol 2008; 41 (6): 567-74.

18. Castro Hevia J, Antzelevitch C, Tornés Bárzaga F, Dorantes Sánchez M, Dorticós Balea F, Zayas Molina R, et al. Tpeak-Tend and Tpeak-Tend dispersion as risk factors for ventricular tachycardia/ventricular fibrillation in patients with the Brugada syndrome. J Am Coll Cardiol 2006; 47 (9): 1828-34.

19. Zhao X, Xie Z, Chu Y, Yang L, Xu W, Yang X, et al. Association between Tpe/QT ratio and prognosis in patients undergoing primary percutaneous coronary intervention for ST-segment elevation myocardial infarction. Clin Cardiol 2012; 35 (9): 559-64.

20. Topilski I, Rogowski O, Rosso R, Justo D, Copperman Y, Glikson M, et al. The morphology of the QT interval predicts torsade de pointes during acquired bradyarrhythmias. J Am Coll Cardiol 2007; 49 (3): 320-8. 